\title{
Germinação e desenvolvimento de mudas do tomateiro Super Marmande submetidos à aplicação de giberelina em diferentes níveis de sombreamento
}

\author{
Ramonn Diego Barros de Almeida * \\ Cristina Moll Huther \\ Ana Claudia Langaro \\ Nathan Pereira da Costa Correa \\ Julia Oliveira \\ Daniela Marques Correa \\ Jóice Azevedo \\ Universidade Federal Fluminense, Campus Praia Vermelha \\ Rua Passo da Pátria, 156, Sala 209, Bloco D, CEP 24.210-240, Niterói - RJ, Brasil \\ * Autor para correspondência \\ ramonnbarros@id.uff.br
}

Submetido em 19/11/2019

Aceito para publicação em 26/03/2020

\section{Resumo}

Devido à crescente importância socioeconômica do fruto do tomateiro, a preocupação acerca da germinação e do crescimento vegetativo dessa espécie é alvo de estudos para seu melhoramento, visando principalmente ao aumento da produtividade. Portanto, objetivou-se avaliar a influência do ácido giberélico e de diferentes níveis de sombreamento na germinação e no desenvolvimento inicial das mudas de tomateiro da variedade Super Marmande. O delineamento experimental foi em blocos ao acaso e os tratamentos arranjados em esquema fatorial (2x3), sendo o fator A com e sem a aplicação do hormônio, Giberelina (GA), na concentração de $200 \mathrm{mg} . \mathrm{L}^{-1}$, e o fator B com três diferentes níveis de intensidade luminosa (pleno sol $(0 \%)$, 70 e $90 \%$ de sombreamento). A germinação e a condução do experimento foram realizadas em bandejas de polietileno com substrato comercial Terral ${ }^{\circledR}$, composto por 20 plantas com 10 repetições cada e as avaliações foram realizadas 26 dias após a semeadura (DAS). Foram analisados taxa de germinação diária, índice de velocidade de germinação, porcentagem de germinação, massa fresca e seca da plântula inteira, volume de raiz, diâmetro do caule, comprimento de raiz e altura da parte aérea e pigmentos fotossintéticos. Os resultados demonstraram que somente os níveis de sombreamento influenciaram na germinação. Já a utilização do ácido giberélico na concentração de $200 \mathrm{mg}$. $\mathrm{L}^{-1}$, para as mudas do tomateiro Super Marmande, não apresentou efeito significativo. O desenvolvimento das mudas nos níveis de sombreamento de $70 \%$ e $90 \%$ foi melhor quando comparado com o tratamento a pleno sol.

Palavras-chave: Ácido giberélico; Intensidade luminosa; Solanum lycopersicum 


\title{
Abstract
}

\begin{abstract}
Germination and development of Super Marmande tomato seedlings submitted to the application of gibberelline in different levels of shading. Due to the tomato growing socioeconomic importance, issues about the germination and the vegetative growth of the species are the aim of studies focusing on its improvement, seeking mostly to increase productivity. Therefore, this work aimed to evaluate the influence of the gibberellic acid and different levels of shading in the germination and initial development of tomato seedlings from the Super Marmande variety. The experimental outline adopted was in randomized blocks, arranged in factorial scheme (2x3), managing the factor A with and without the application of the hormone, Gibberellin (GA), at a concentration of $200 \mathrm{mg} . \mathrm{L}^{-1}$, and the factor B in three different levels of luminous intensity (full sun ( $0 \%$ ), 70 and $90 \%$ shading). The germination and the conduction of the experiment were carried out in polyethylene trays with commercial substrate Terral ${ }^{\circledR}$, composed of 20 plants with 10 repetitions each and the evaluations were carried out 26 days after sowing (DAS). Analysis were led on germination rate, germination speed index, germination percentage, fresh mass, fresh mass, total dry biomass, root volume, stem diameter, root length, the height of aerial part and photosynthetic pigment. Results pointed out that only the levels of shading affected the germination. The application of gibberellic acid for the Super Marmande tomato did not reveal a significant effect. The development of seedlings in the shading of $70 \%$ and $90 \%$ was better when compared to the full sun treatment.
\end{abstract}

Key words: Gibberellic acid; Solanum lycopersicum; Tomato

\section{Introdução}

O Brasil é um dos maiores produtores de hortifruticultura do mundo, sendo o tomateiro (Solanum lycopersicum) uma cultura de elevado interesse econômico para o país (CAMARGO FILHO; CAMARGO, 2017). A produção do tomate é conhecida por ser uma lavoura de difícil manejo, pois requer mão de obra especializada e diversos cuidados, devido à alta suscetibilidade a pragas e doenças que podem acarretar a perda de produtividade (PIMENTA JUNIOR et al., 2016).

Iniciar a produção a partir de mudas de boa qualidade e uniformes, sem a presença de microrganismos que podem trazer anomalias para as plantas, resulta em uma produção mais eficiente (BATISTA et al., 2015). Por isso, se fazem necessárias pesquisas que visem buscar a melhor forma de obter mudas de tomateiro com qualidade elevada, desde o início da germinação, até o desenvolvimento da plântula. Assim alguns trabalhos têm buscado melhores informações acerca dos aspectos germinativos e desenvolvimento de plântulas na cultura do tomateiro (AYUB; REZENDE, 2010; BORGES et al., 2018).

Ainda alguns fatores abióticos estão diretamente relacionados ao bom desenvolvimento das plantas, sendo capaz, por exemplo, de melhorar a qualidade das mudas (CAMPANHARO et al., 2006). Pesquisas demonstram que o uso de hormônios, como o ácido giberélico (GA), em tratamento de sementes pode facilitar a germinação e o desenvolvimento inicial das plântulas, como ocorreu no maracujazeiro (SANTOS et al., 2013), romãzeira (TAKATA et al., 2014), arroz (RODRIGUES et al., 2015) e tomate (PIMENTA JUNIOR et al., 2016).

O nível de intensidade luminosa também é outro fator que está diretamente relacionado ao crescimento e desenvolvimento das plantas, pois, dependendo do ambiente em que as plantas se encontram, este pode influenciar na quantidade e na qualidade de luz que chega, uma vez que o número de cloroplastos por volume celular depende do desenvolvimento e de seu ambiente (TAIZ et al., 2017) e, dependendo da espécie, pode ocorrer ajuste no sistema antena, a fim de se aclimatar ao nível de intensidade luminosa, para favorecer o seu crescimento (MATOS et al., 2011; ROGOWSKI et al., 2019), o que já foi observado para as mudas de jenipapo-bravo (Tocoyena formosa) (BONAMIGO et al., 2016) e salsinha (Petroselinum crispum) (LAURENTINO; MINUZZI, 2018). Outros autores também relatam que algumas espécies amazônicas respondem com diferentes formas de desenvolvimento quando submetidas a variações de sombreamento (CAMPOS; UCHIDA, 2002). 
Portanto, o objetivo deste trabalho foi avaliar a influência do ácido giberélico e de diferentes níveis de sombreamento na germinação e no desenvolvimento inicial das mudas de tomateiro da variedade Super Marmande.

\section{Material e Métodos}

O experimento foi realizado na Universidade Federal Fluminense, em área experimental localizada no campus Gragoatá, na cidade de Niterói/RJ, latitude de $22^{\circ} 54^{\prime} 00$ 'S, longitude de $43^{\circ} 08^{\prime} 00^{\prime \prime} \mathrm{W}$ e altitude de $8 \mathrm{~m}$, pertencente ao programa Fitoterápico Farmácia Viva em parceria com o Programa de Pós Graduação em Engenharia de Biossistemas.

Foram utilizadas 1.200 sementes de tomate Super Marmande, do grupo ISLA PAK ${ }^{\circledR}$. O delineamento experimental adotado em blocos ao acaso e os tratamentos arranjados em esquema fatorial ( $2 \times 3)$, sendo o fator A a aplicação ou não do hormônio GA na concentração de $200 \mathrm{mg}$. $\mathrm{L}^{-1}$ e o fator B três diferentes níveis de intensidade luminosa (pleno sol (0\%), 70\% e $90 \%$ de sombreamento). Cada unidade experimental foi composta por 20 plantas com 10 repetições cada.

As sementes foram divididas em dois grupos, metade das sementes foi imersa, por aproximadamente 30 minutos, em uma solução aquosa (água destilada + $200 \mathrm{mg} . \mathrm{L}^{-1} \mathrm{de}$ GA) e uma outra metade apenas em água destilada, pelo mesmo período de tempo. As sementes foram semeadas em bandejas de polietileno, com 200 células, e preenchidas com o substrato comercial Terral ${ }^{\circledR}$, composto por terra vegetal e esterco bovino. As bandejas foram acondicionadas em áreas de diferentes níveis de sombreamento, pleno sol ( $0 \%$ ) e casas de vegetação com sombreamentos de $70 \%$ e $90 \%$.

A taxa de germinação foi aferida diariamente, até o décimo oitavo dia, quando todos os tratamentos já não apresentavam mais sementes em fase germinativa, levando em consideração que todas as sementes germinadas apresentavam mais de $2 \mathrm{~mm}$ de comprimento. Foram determinadas a taxa de germinação diária, a porcentagem de germinação e o índice de velocidade de germinação (IVG). A porcentagem de germinação foi calculada pela fórmula proposta nas Regras para Análise de Sementes (BRASIL, 2009) e o IVG de acordo com a equação (EQ (1)) proposta por Maguire (1962) adaptado de Moraes et al. (2012).

$I V G=(G 1 / N 1)+(G 2 / N 2)+\ldots+(G n / N n) \quad E Q(1)$

Onde:

G1, G2, Gn = número de sementes germinadas na primeira, segunda e última contagem.

$\mathrm{N} 1, \mathrm{~N} 2, \mathrm{Nn}=$ dias após a semeadura na primeira, segunda e última contagem.

Das mudas obtidas, aos 26 dias após a semeadura (DAS), obtivemos os dados de massa da matéria fresca e seca, altura da parte aérea, comprimento e volume de raiz e diâmetro do caule na altura do cólon. Foi selecionada ao acaso uma muda de cada repetição para medição dos itens mencionados.

As mensurações do tamanho de parte aérea e de raiz foram realizadas com régua graduada, do colo da planta até seu ápice foliar e do colo até seu ápice radicular, respectivamente. As mensurações do diâmetro do caule na altura do colo sendo realizadas com paquímetro digital. O volume do sistema radicular foi obtido pelo deslocamento de água em proveta graduada. As matérias fresca e seca totais das plantas foram obtidas por balança de precisão, sendo a matéria seca após a secagem em estufa de ventilação forçada à temperatura de $65 \pm 2^{\circ} \mathrm{C}$, até atingir peso constante. Não foi realizada a separação por partes da planta.

A determinação do teor de pigmentos fotossintéticos (Clorofila $a, b$ e Carotenoides) foi feita de acordo com Arnon (1949). Amostras de 0,070 g de tecido foliar proveniente das folhas foram maceradas na presença de acetona $80 \%$ e estimadas; para a leitura, utilizou-se espectrofotômetro UV-340G, nos comprimentos de onda para carotenoides $(450 \mathrm{~nm})$, clorofila $b(645 \mathrm{~nm}) \mathrm{e}$ clorofila $a(663 \mathrm{~nm})$. A partir das leituras de absorbância, foram realizadas determinações do teor de pigmentos conforme Hendry e Gryme (1993) e expressas em $\mu$ mol.g ${ }^{-1}$ de massa fresca foliar.

Todos os dados foram submetidos à análise de variância com auxílio do programa $\mathrm{SAS}^{\circledR}$ e, quando significativos, as médias foram comparadas pelo teste de Tukey, a 5\% de probabilidade. 


\section{Resultados}

A taxa de germinação, acompanhada diariamente até os $18 \mathrm{DAS}$, foi maior para as plantas que foram conduzidas nos sombreamentos de 70 e $90 \%$

(Figura 1) e, estatisticamente, não apresentou significância $(p>0,05 ; F=0,003)$ entre a utilização ou não do GA. O

FIGURA 1: Taxa de germinação aferida diariamente até os 18 DAS. Níveis de intensidade Luminosa: (A) pleno sol, (B) 70\% e (C) 90\%

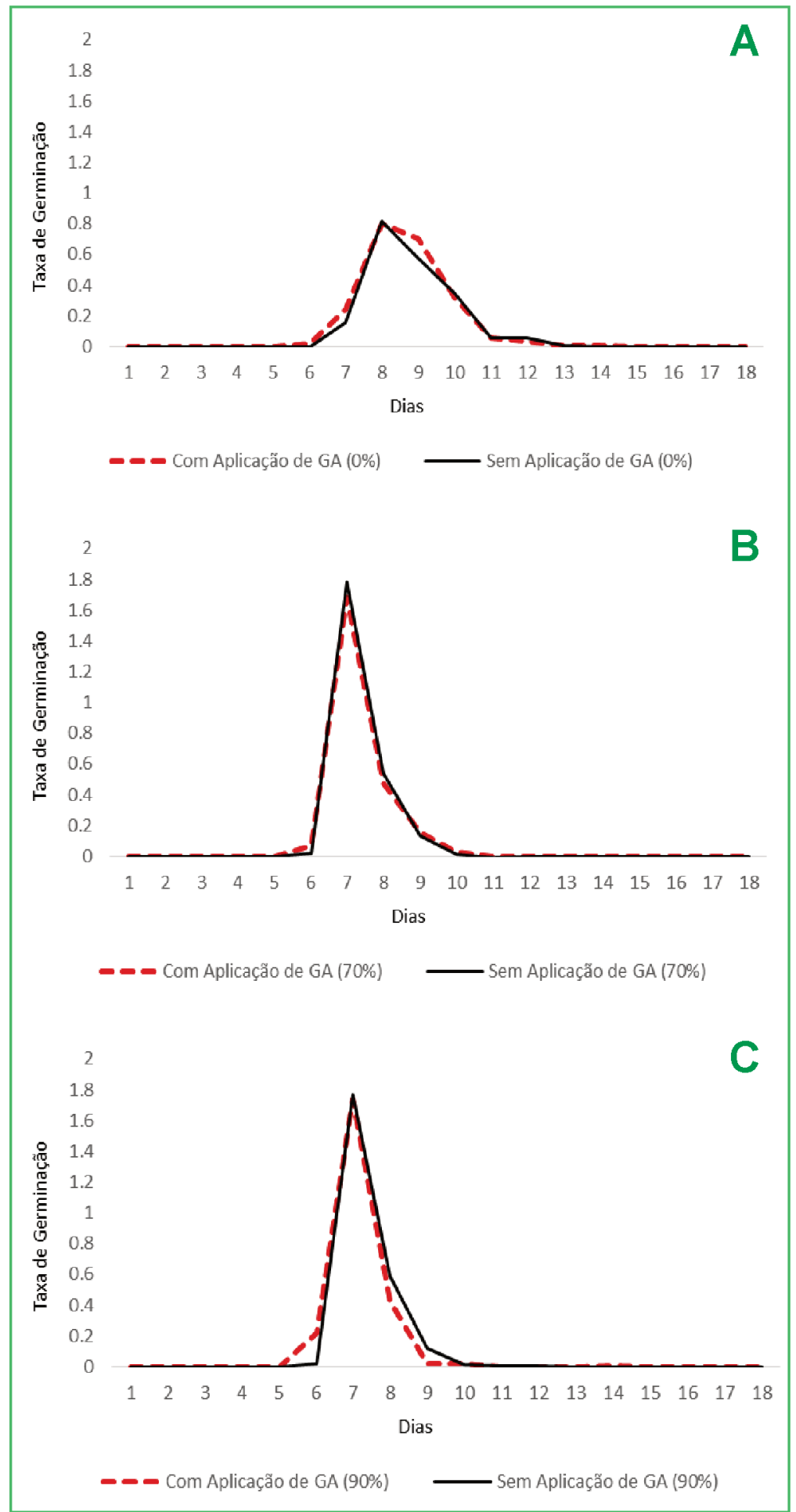


tratamento conduzido a pleno sol foi o que obteve menor taxa de germinação em comparação com os tratamentos de 70 e $90 \%$ de sombreamento.

Foi observada diferença estatística, quanto à média do Índice de Velocidade de Germinação (IVG), entre os tratamentos conduzidos a 70 e $90 \%$ de sombreamento (Tabela 1), sendo diferentes somente do tratamento conduzido a pleno sol $(0 \%)$.

TABELA 1: Índice de velocidade de germinação (IVG) de sementes de tomate submetidas a diferentes níveis de intensidade luminosa.

\begin{tabular}{cc} 
Sombreamento & $\begin{array}{c}\text { Índice de Velocidade de } \\
\text { Germinação }\end{array}$ \\
\hline $0 \%$ & $2,10 \mathrm{~b}$ \\
$70 \%$ & $2,44 \mathrm{a}$ \\
$90 \%$ & $2,48 \mathrm{a}$ \\
\hline $\mathrm{CV}(\%)$ & 11,34 \\
$\mathrm{~F}$ & 12,45 \\
\hline
\end{tabular}

* Médias seguidas pela mesma letra na coluna não diferem estatisticamente entre si pelo Teste de Tukey ao nível de 5\% de probabilidade.

A maior porcentagem de germinação inicial foi observada nos tratamentos de 70 e $90 \%$ de sombreamento, contudo, aos 10 DAS, todos os tratamentos apresentaram variações de porcentagem de germinação (Figura 2) semelhantes, variando entre $87-93 \%$ das sementes germinadas em cada tratamento.
Quando analisada a interação entre diferentes níveis de intensidade luminosa com aplicação de GA, para todas as variáveis analisadas, massa fresca $(p>0,05 ; F=12,68)$, massa seca $(p>0,05 ; F=4,39)$, volume de raiz ( $\mathrm{p}>0,05 ; \mathrm{F}=6,43)$, diâmetro do caule $(\mathrm{p}>0,05 ; \mathrm{F}=9,83)$, tamanho raiz $(\mathrm{p}>0,05 ; \mathrm{F}=1,91)$, altura parte aérea $(p>0,05 ; F=23,12)$, não se observou diferença significativa, entre os tratamentos, sem efeito da aplicação de GA. Somente os diferentes níveis de luminosidade apresentaram efeito sobre a germinação e o desenvolvimento das plântulas (Tabela 2).

Entre as variáveis analisadas, pode-se destacar que, com exceção da massa seca e do comprimento de raiz, as variações significativas ocorreram nas plântulas conduzidas nos tratamentos de 70 e $90 \%$ de sombreamento. No que tange ao comprimento de raiz, os diferentes níveis de intensidade luminosa não acarretaram ganho ou perda nas medidas.

As análises de pigmentos fotossintéticos (clorofila $a$ e $b$ e carotenoides) só foram realizadas nas mudas que foram acondicionadas em casa de vegetação com sombreamento de 70 e $90 \%$, pois as mudas que foram conduzidas a pleno sol tiveram um elevado estresse luminoso, o que as deixaram com uma desproporção em relação ao tamanho e com quantidade de massa fresca inferior à necessária para as análises. Não houve significância estatística para a clorofila $a(\mathrm{p}>0,005$; $\mathrm{F}=1,26)$, clorofila $b(\mathrm{p}>0,005 ; \mathrm{F}=1,07)$ e carotenoides $(p>0,005 ; F=1,07)$, ou seja, os tratamentos em questão não alteraram o teor de pigmentos.

TABELA 2: Parâmetros de desenvolvimento de plântulas de tomate submetidas a diferentes níveis de intensidade luminosa.

\begin{tabular}{ccccccc}
\hline Sombreamento & $\begin{array}{c}\text { Massa Fresca } \\
(\mathbf{g})\end{array}$ & $\begin{array}{c}\text { Massa Seca } \\
(\mathbf{g})\end{array}$ & $\begin{array}{c}\text { Comprimento } \\
\text { Parte Aérea } \\
(\mathbf{c m})\end{array}$ & $\begin{array}{c}\text { Comprimento } \\
\text { Raiz } \\
(\mathbf{c m})\end{array}$ & $\begin{array}{c}\text { Volume Raiz } \\
(\mathbf{m L})\end{array}$ & $\begin{array}{c}\text { Diâmetro } \\
\text { Caule } \\
(\mathbf{m m})\end{array}$ \\
\hline $0 \%$ & $0,05 \mathrm{~b}$ & $0,01 \mathrm{~b}$ & $2,99 \mathrm{~b}$ & $4,88 \mathrm{a}$ & $0,05 \mathrm{~b}$ & $1,39 \mathrm{~b}$ \\
$70 \%$ & $0,17 \mathrm{a}$ & $0,02 \mathrm{a}$ & $6,26 \mathrm{a}$ & $6,01 \mathrm{a}$ & $0,21 \mathrm{a}$ & $1,30 \mathrm{a}$ \\
$90 \%$ & $0,16 \mathrm{a}$ & $0,01 \mathrm{~b}$ & $7,26 \mathrm{a}$ & $5,22 \mathrm{a}$ & $0,26 \mathrm{a}$ & $1,39 \mathrm{a}$ \\
\hline $\mathrm{CV}(\%)$ & 42,16 & 65,78 & 24,08 & 24,08 & 77,77 & 16,94 \\
$\mathrm{~F}$ & 31,17 & 8,68 & 56,55 & 3,04 & 14,27 & 23,37 \\
\hline
\end{tabular}

* Médias seguidas pela mesma letra na coluna não diferem estatisticamente entre si pelo Teste de Tukey ao nível de 5\% de probabilidade. 
FIGURA 2: Percentual de germinação de sementes de tomate submetidas a diferentes níveis de intensidade luminosa em função do tempo (dias). Níveis de intensidade Luminosa: (A) pleno sol, (B) 70\% e (C) $90 \%$.

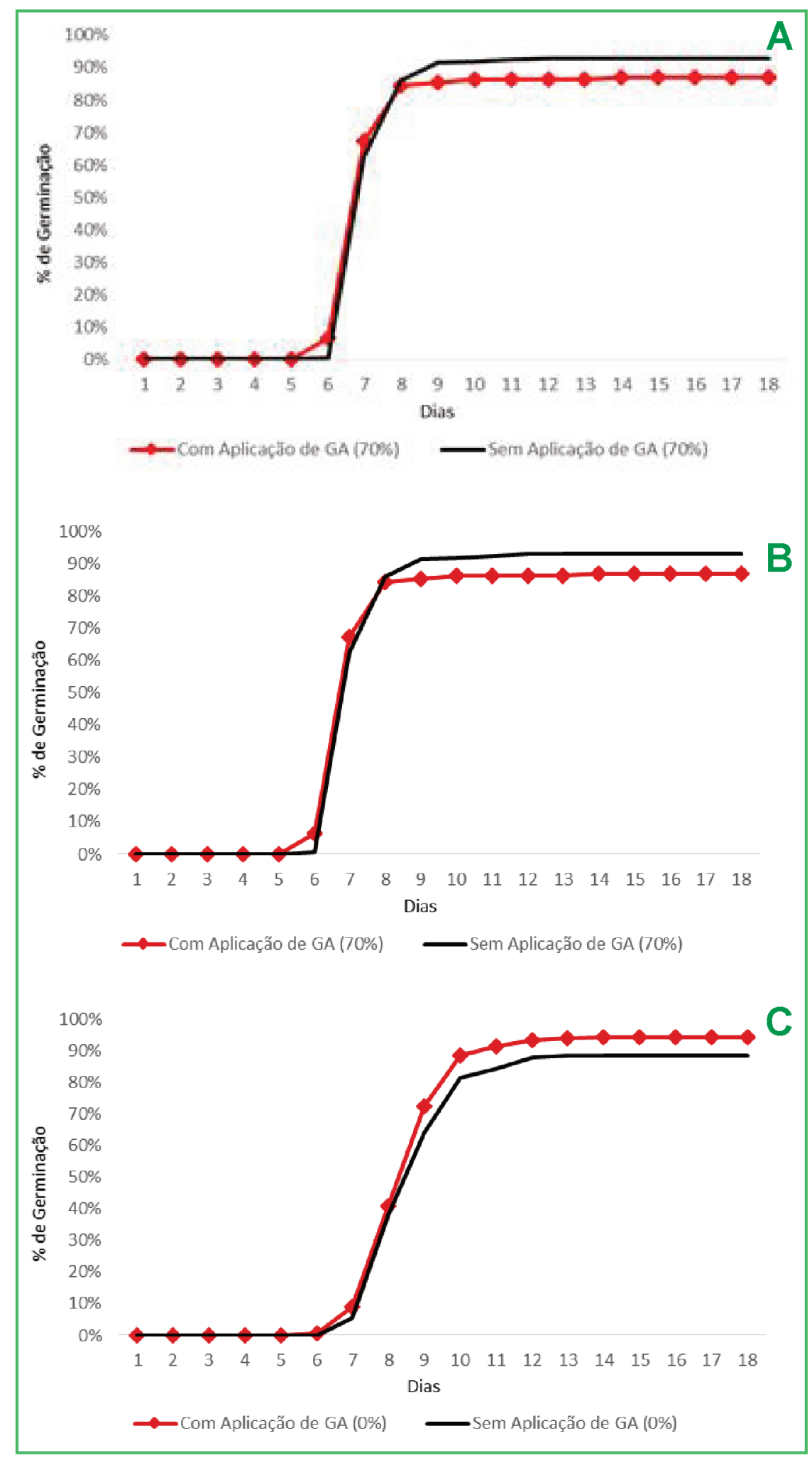




\section{Discussão}

De modo geral, em todos os tratamentos, o percentual de germinação estabilizou entre $87-93 \%$ das sementes germinadas, o que pode estar relacionado ao fato de o tomateiro ser indiferente quanto à necessidade de maior ou menor intensidade de luz no momento da germinação, ou seja, a sua porcentagem de germinação é semelhante em todos os níveis de intensidade de luz aos quais foi exposto (SILVA et al., 2012).

No que diz respeito às análises com relação aos parâmetros de desenvolvimento das mudas do tomateiro, foi possível constatar que, com exceção da matéria seca e do comprimento de raiz, quanto menor a intensidade luminosa até 26 DAS, maior é o desenvolvimento do parâmetro analisado. A menor intensidade luminosa pode acarretar um maior número de clorofila para suprir as demandas fisiológicas da plântula, o que requer maior crescimento da parte aérea em busca de luz. Os resultados corroboram Paiva et al. (2003) para mudas de cafezeiro e que também foram verificados por Freitas et al. (2011) para as mudas de maracujá-doce.

Em relação ao tratamento a pleno sol, que influenciou negativamente no comprimento da parte aérea, pode ser justificado devido à alta intensidade luminosa, está pode contribuir ou inibir o alongamento do hipocótilo em plântulas, conforme abordam Taiz et al. (2017). Devido ao excesso de energia, ocorre a fotoxidação da planta e, dessa forma, o processo fotossintético não é eficiente, podendo ocorrer a formação de oxigênio singleto, que ativa as enzimas antioxidantes, ocasionando estresse na planta e prejuízo no seu desenvolvimento, aliados aos gastos enérgicos para tentar amenizar os efeitos da fotoinibição causada.

Não houve variação significante dos pigmentos fotossintéticos em relação aos diferentes níveis de intensidade luminosa, principalmente a clorofila $a$, que é o pigmento primordial para que ocorram os processos de transições eletrônicas e as reações de redox (TAIZ et al, 2017). Entretanto, Brito et al. (2018), também em plantas de tomateiro ('Sweet Heaven'), verificaram que a partir dos 59 DAS, quando as plantas foram expostas a diferentes níveis de intensidade luminosa, estas apresentavam um maior índice de clorofila $a$ e $b$ nas plantas conforme aumentava a intensidade luminosa. No entanto, os autores fizeram as análises pelo método do clorofilômetro, método diferente do utilizado neste trabalho.

O ácido giberélico pode influenciar na germinação da semente do tomate conforme referências citadas anteriormente, pois ele estimula o alongamento celular, fazendo com que a radícula rompa o tegumento da semente (TAIZ et al., 2017). No entanto, no presente estudo as sementes de tomate apresentaram uma germinação natural elevada, conforme pode ser observado no tratamento controle do GA (Figura 2), o que provavelmente contribuiu para o não efeito da aplicação do ácido giberélico, o que também pode estar relacionado com o tempo em que eles ficaram em contato.

O ácido giberélico aplicado nas sementes de tomate Super Marmande na concentração de $200 \mathrm{mg}$. $\mathrm{L}^{-1}$ não proporcionou efeito fisiológico na germinação, no crescimento e desenvolvimento das plântulas, já os diferentes níveis de luminosidade afetaram o ganho de biomassa e o vigor das mudas, de tal modo que as menores intensidades luminosas proporcionaram melhor qualidade das mudas.

\section{Agradecimentos}

O presente trabalho foi realizado com apoio da Coordenação de Aperfeiçoamento de Pessoal de Nível Superior - Brasil (CAPES) - Código de Financiamento 001, Conselho Nacional de Desenvolvimento Científico e Tecnológico CNPq e Fundação de Amparo à Pesquisa do Estado do Rio de Janeiro - FAPERJ.

\section{Referências}

ARNON, D. I. Copper enzymes in isolated chloroplasts: polyphenoloxydase in Beta vulgaris. Plant Physiology, Maryland, v. 24, p. 1-15, 1949.

AYUB, R. A.; REZENDE, B. L. A. Contribuição do ácido giberélico no tamanho de frutos do tomateiro. Biotemas, Florianópolis, v. 23, n. 4, p. 25-28, 2010.

BATISTA, T. B.; BINOTTI, F. F. S.; CARDOSO, E. D.; BARDIVIESSO, E. M.; COSTA, E. Aspectos fisiológicos e qualidade de mudas da pimenteira em resposta ao vigor e 
condicionamento das sementes. Bragantia, Campinas, v. 74, n. 4, p. 367-373, 2015.

BRASIL. Regras para análise de sementes. Brasilia: MAPA/ ACS, 2009. 395 p.

BONAMIGO, T.; SCALON, S. P. Q.; PEREIRA, Z. V. Substratos e níveis de luminosidade no crescimento inicial de mudas de Tocoyena formosa (Cham. \& Schltdl.) K. Schum. (Rubiaceae). Ciência Florestal, Santa Maria, v. 26, n. 2, p. 501-511, 2016.

BORGES, R. P.; NOGUEIRA, L. T.; CECCHIN, D.; PEREIRA, C. R.; HUNTER, C. M. Germinação de sementes de tomate submetidas a diferentes concentrações de cloreto de sódio e substratos. Enciclopédia Biosfera, Goiânia, v. 15, n. 28, p. 571577, 2018.

BRITO, A. M.; FERNANDES, G. S. T.; NETO, A. M.; LIMA, E. A.; CHAVES, D. V. Influência da luminosidade no teor de clorofila do tomateiro 'sweet heaven' sob diferentes doses de bioestimuante. In: CONGRESSO TÉCNICO CIENTÍFICO DA ENGENHARIA E DA AGRONOMIA, 2018, Maceió. Anais... Maceió: CONTECC, 2018. Versão eletrônica.

CAMARGO FILHO, W. P.; CAMARGO, F. P. A quick review of the production and commercialization of the main vegetables in Brazil and the world from 1970 to 2015 . Horticultura Brasileira, Brasília, v. 35, n. 2, p. 160-166, 2017.

CAMPANHARO, M.; RODRIGUES, J. J. V.; JUNIOR, M.; ESPINDULA, M. C.; COSTA J. V. T. Características físicas de diferentes substratos para produção de mudas de tomateiro. Caatinga, Mossoró, v. 19, p. 40-145, 2006.

CAMPOS, M. A. A.; UCHIDA, T. Influência do sombreamento no crescimento de mudas de três espécies amazônicas. Pesquisa Agropecuária Brasileira, Brasília, v. 37, n.3, p. 281-288, 2002.

FREITAS, A. R.; VENANCIO L. P.; LOPES, J. C. Influência de diferentes níveis de sombreamento sobre o crescimento de mudas de maracujá-doce (Passiflora alata Curtis). In: ENCONTRO LATINO AMERICANO DE INICIAÇÃO CIENTÍFICA, XIV, 2011, São José dos Campos. Anais... São José dos Campos: Encontro Latino Americano de Iniciação Científica. 2011. Versão eletrônica.

LAURENTINO, M.; MINUZZI, R. B. Características comerciais da salsa em ambientes cobertos com malhas de sombreamento e foto conversora durante o verão na região de Imaruí, Santa Catarina. Revista Brasileira de Agropecuária Sustentável, Viçosa, v. 8, n. 3, p. 35-40, 2018.

MAGUIRE, J. D. Speed germination-aid in selection and evaluation for seedling emergence and vigor. Crop Science, Madison, v. 2, p. $176-177,1962$.
MATOS, F. S.; GAMBOA, I.; RIBEIRO, R. P.; MAYER, M. L.; NEVES, T. G.; LEONARDO, B. R. L.; SOUZA, A. C. Influência da intensidade luminosa no desenvolvimento de mudas de pinhão manso L. Agrarian, Dourados, v. 4, n. 14, p. 265-272, 2011.

MORAES, D. M.; BANDEIRA, J. de M.; MARINI, P.; LIMA, M. G. S.; MENDES, C. R. Práticas laboratoriais em Fisiologia Vegetal. Vol. 1. Pelotas: Editora Copias Santa Cruz Ltda, 2012. 162 p.

PAIVA, L. C.; GUIMARÃES, R. J.; SOUZA, C. A. S. Influência de diferentes níveis de sombreamento sobre o crescimento de mudas de cafeeiro (Coffea arabica L.). Ciência e Agrotecnologia, Lavras, v. 27, n. 1 , p. 134-140, 2003.

PIMENTA JUNIOR, O. M. P.; RIBEIRO, V. A.; MILHOMEM, A. M. P. Avaliação de mudas do tomateiro sob influência de bioestimuladores. Revista Científica, Maracaibo, v. 3, n. 2, p. 37 , 2016.

RODRIGUES, L. A.; BATISTA, M. S.; ALVAREZ, R. C. F.; LIMA, S. F.; ALVES, C. Z. Avaliação fisiológica de sementes de arroz submetidas a doses de bioestimulante. Nucleus, Ituverava, v. 12, n. 1, p. 207-214, 2015.

ROGOWSKI, P.; WASILEWSKA-DĘBOWSKA, W.; KRUPNIK, T.; DROŻAK, A.; ZIENKIEWICZ, M.; KRYSIAK, M.; ROMANOWSKA, E. Photosynthesis and organization of maize mesophyll and bundle sheath thylakoids of plants grown in various light intensities. Environmental and Experimental Botany, Paris, v. 162, p. 72-86, 2019.

SANTOS, C. A. C.; VIEIRA, E. L.; PEIXOTO, C. P.; SILVA L. C. A. Germinação de sementes e vigor de plântulas de maracujazeiro amarelo submetidos à ação do ácido giberélico. Bioscience Journal, Uberlândia, v. 29, n. 2, p. 400-407, 2013.

SILVA, J. H. K.; PEREIRA, T. M.; NASCIMENTO, J. W.; TANNURE, F. P.; DUARTE, M. M. Germinação e crescimento inicial de tomate italiano (Lycopersicon esculentum Mill.): efeitos do fotoperíodo. Natureza On Line, Santa Teresa, v. 10, n. 4, p. 183-185, 2012.

TAIZ, L.; ZEIGER, E.; MØLLER, I. M.; MURPHY, A. Fisiologia e desenvolvimento vegetal. 6. ed. Porto Alegre: Artmed, 2017. $888 \mathrm{p}$.

TAKATA, W.; SILVA E. G.; CORSATO, J. M.; FERREIRA G. Germinação de sementes de romãzeiras (Punica granatum L.) de acordo com a concentração de giberelina. Revista Brasileira de Fruticultura, Jaboticabal, v. 36, n. 1, p. 254-260, 2014. 